\title{
Mathematical Modelling and Performance Analysis of Flat Plate Solar Dryer- CFD Simulation Approach
}

\begin{abstract}
Debela Geneti Desisa ${ }^{1, a, *}$
${ }^{1}$ Faculty of Mechanical Engineering, Jimma Institute of Technology, Jimma University, Ethiopia * Corresponding author

A R T I C L I N F O A B S T R A C T

Research Article

This study focuses on the investigation of enhancing convective heat transfer between the absorber and the air inside a channel. The investigation approaches modelling different absorber through CFD simulation and validating the result with experimental data. Supplying air to both sides of the top and the bottom surfaces of the absorber increase the air mass flow rate and therefore increases the thermal efficiency of the dryer. The studies in a V-grooved absorber attain high hot air velocity; high thermal efficiency resulted from high turbulence created in the duct. For the sample taken with a flow range, $0.01 \mathrm{~kg} / \mathrm{s}$ to $0.06 \mathrm{~kg} / \mathrm{s}$, the high output temperature was observed in a lower temperature range and increases as the flow rate increases. At a flow rate $0.01 \mathrm{~kg} / \mathrm{s}$, the velocity of hot air passing over the V-grooved absorber attain $0.28 \mathrm{~m} / \mathrm{s}$ and increased to $1.4 \mathrm{~m} / \mathrm{s}$ as the mass flow rate increased to $0.06 \mathrm{~kg} / \mathrm{s}$. For the rectangular absorber, the velocity of hot air attains $0.15 \mathrm{~m} / \mathrm{s}$ at a flow rate of $0.01 \mathrm{~kg} / \mathrm{s}$ and increased to $1.46 \mathrm{~m} / \mathrm{s}$ as the mass flow rate increases to $0.06 \mathrm{~kg} / \mathrm{s}$. The double-sided $\mathrm{V}$-grooved absorber contributes $8-12.40 \%$ value more efficiency compared to the rectangular plate with the same flow orientation. Further investigation is recommended taking the quantitative analysis obtained in this study and generating qualitative data.

Keywords:

- grooved

CFD simulation

Mathematical modelling
\end{abstract}

Flowrate

\section{Introduction}

The growing demand for thermal energy in the residential sector and some industrial applications are the first precondition to sustain the steps of renewable energy technology development. Concatenation works are going in the world in this sector to abolish fossil fuel energy sources. In need of enhancing the traditional solar air heater (SAH) performance, the solar dryer has been widely used to convert solar insolation to thermal energy. The flat plate solar dryer is applicable for numerous applications; drying farm products, air heating, drying seeds and vegetables, and also in some modern applications.

Attaching fins to the absorber increases convective heat transfer and also collector efficiency (Priyam and Chand, 2016). The presence of obstacles in the airflow stream creates turbulence that enhances the interaction of air molecules and contact with the absorber surface (Handoyo et al., 2016; R. Kumar et al., 2018). This leads to upgrade the performance of a collector, as a result, the thermal efficiency also improved. The heat transfer between the absorber and flowing fluid can be improved by either increasing the convective heat surface area using extended and corrugated surfaces without enhancing the heat transfer coefficient or by increasing the heat transfer coefficient using the turbulence promoters in the form of artificial roughness on a heated plate (A. Kumar and Kim, 2017; Shukla et al., 2018)

Different studies have been done in increasing the thermal efficiency of flat plate solar dryer incorporating single and double-sided airflow. Enhancing solar thermal performance incorporating different flow stream guider i.e. V-groove, helical fins, rectangular baffles, wire mesh, inclined ribs, and having rectangular duct with chamfered square roughness elements on the absorber plate (Liu et al., 2007; Ho et al., 2016; Karim and Hawlader, 2006; Chabane et al., 2014; Aravindh and Sreekumar, 2016; Bharadwaj et al., 2017; Azad et al., 2018; Prakash and Saini, 2019) increase the convective heat transfer. 
Solar drier performance influenced by various parameters; the temperature of the gas (Burmester and Eggers, 2010), thermal efficiency (A.Singh and Singh, 2018), thermal conductivity, and convective drying effects in fluid suspension and flow rate (Sadeghzadeh et al., 2019), heat transfer between flowing air and absorber (Fudholi et al., 2015; Zulkifle et al., 2018), types of airflow patterns (Alam and Kim, 2017), the optimum value of geometric parameters and minimization of surface friction losses (Alam et al. 2014). The parametric study was done by Rai et al., 2017 on fin height, air mass flow rate and the insolation are indicates more effective in increasing thermohydraulic and also thermal performance. The conventional and staggered fins solar air heater coated with CNT-black paint enhances the heat transfer of SAH improving the plate temperature (Madhu et al., 2020).

The numerical study was more effective tool than an experimental study due to cheaper cost, short time to study different parameters, and no system setup (Olia et al., 2019). However, CFD simulation never gets rid of the claim to construct and test prototypes, but it can significantly decrease the number of tests normally needed in the empirical analysis. Thus, CFD is contemplated as a general and valuable tool for the analysis of flow behaviour and problems dealt with predicting its behaviour and a better understanding of new design before manufacturing (Khatibi et al.,2019). In different disciplines and industries, modelling and simulation provide treasures solutions providing a clear understanding of complex geometries.

The motivation for this work is to scan a feasible solar crop drier through CFD simulation and developing a mathematical model to build and test a prototype. An appropriate drying method is a vital role to extend the shelf life of the agricultural product and reduce volume with the desired quality. Analysis of thermal energy required for drying different agricultural products is necessary to ensure the thermal energy supplied is sufficient or not sufficient from analyses of heat transfer inside a collector.

The objective of the present study is therefore to obtain theoretical predication of optimum solar crop dryer through CFD simulation analysis of double-sided airflow over V-grooved absorber and to study the effect of air mass flow rate in improving parameters influencing the dryer.

\section{Material and Methods}

\section{Climate Data Collection}

The study site location, Jimma University, Ethiopia, found at Latitude $7^{\circ} 41^{\prime} 3.59^{\prime \prime} \mathrm{N}$ and longitude $36^{\circ} 49^{\prime} 31.79^{\prime}$ ' $\mathrm{E}$, moderate climate with cold winter and hot summer. The average solar radiation daily reaching the earth's surface is estimated at $5.5 \mathrm{kWh} / \mathrm{m}^{2} /$ day which runs from a minimum value of $4.5 \mathrm{kWh} / \mathrm{m}^{2} /$ day in July to a maximum value of $6.5 \mathrm{kWh} / \mathrm{m}^{2} /$ day in February and March (Tesema, 2014).

\section{Detail Geometry Design and Parameters}

The collector dimension length, width, and height are $2000 \mathrm{~mm} \times 1200 \mathrm{~mm} \times 100 \mathrm{~mm}$ respectively with the $5 \mathrm{~mm}$ thick glass cover, while the drying cabinet is $1200 \mathrm{~mm} \mathrm{x}$ $650 \mathrm{~mm} \times 1000 \mathrm{~mm}$ (width $\mathrm{x}$ depth $\mathrm{x}$ height). The side and bottom of the collector are insulated by glass wool shielded by aluminium foil and wood respectively. The air gap between the upper glass cover and the absorber plate as well as the absorber plate and the bottom side is $50 \mathrm{~mm}$, Figure 1. The total area of the collector is $2.40 \mathrm{~m}^{2}$ and the model has a $45^{\circ}$ inclined surface oriented to the north-south direction where overhead solar radiation is obtained between 11:30 am to 1:00 pm.

Figure 1 (a) shows a single-pass double-sided airflow channel with a flat plate absorber and figure1 (b) shows a $\mathrm{V}$-grooved absorber with the same airflow orientation. In both designs, the absorber is metal black painted both top and bottom surface and kept in the middle of the channel to pass the air over and under it.

The flow with high-velocity strikes the leading surface and deflected toward the absorber area forming a recirculation zone in the case of a V-grooved absorber.

\section{Mathematical Modelling}

A mathematical model is a description of a system using mathematical concepts and language. It is the art of translating a system in an application domain into manageable mathematical formulations whose theoretical and numerical analysis helps to explain a process to provide insight, answers, and useful guidance for the originating application and make predictions about the behaviour of the system.

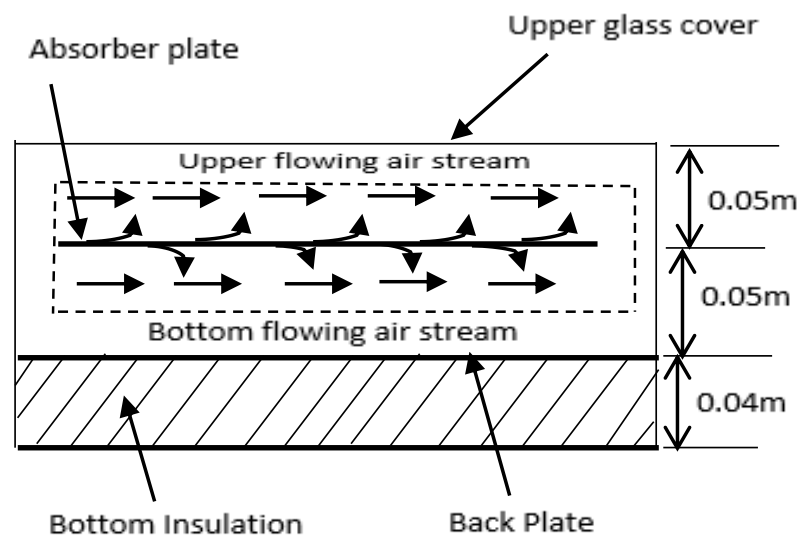

a) Rectangular plate absorber

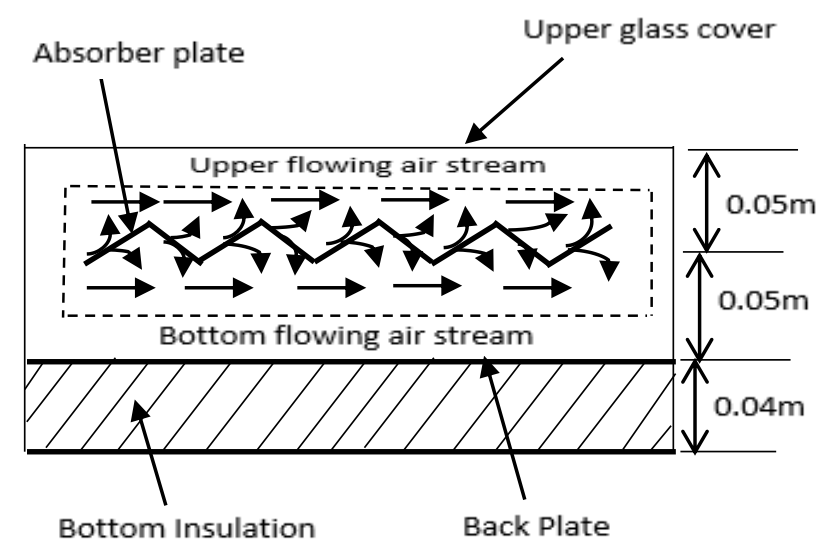

b) V-grooved absorber

Figure 1. double-sided airflow 
The heat balance of the collector cover derived from the thermal network described in Eq. (1) to (3)

$\mathrm{I}_{\mathrm{t}} \alpha_{c}\left(\mathrm{~h}_{\mathrm{c}, \mathrm{p}-\mathrm{c}}+\mathrm{h}_{\mathrm{r}, \mathrm{p}-\mathrm{c}}\right)\left(\mathrm{T}_{\mathrm{p}}-\mathrm{T}_{\mathrm{c}}\right)=\left(\mathrm{h}_{\mathrm{w}}+\mathrm{h}_{\mathrm{r}, \mathrm{c}-\mathrm{s}}\right)\left(\mathrm{T}_{\mathrm{c}}-\mathrm{T}_{\mathrm{a}}\right)=\mathrm{U}_{\mathrm{T}}\left(\mathrm{T}_{\mathrm{c}}-\mathrm{T}_{\mathrm{a}}\right)$

$I_{t} \alpha_{c}\left(h_{c, p-c}+h_{r, p-c}\right) T_{p}+\left(-h_{c, p-c}-h_{r, p-c}\right) T_{c}=U_{T} T_{c}-U_{T} T_{a}$

$\mathrm{I}_{\mathrm{t}} \alpha_{\mathrm{c}}+\mathrm{U}_{\mathrm{T}} \mathrm{T}_{\mathrm{a}}=\left(\mathrm{U}_{\mathrm{T}}+\mathrm{h}_{\mathrm{c}, \mathrm{p}-\mathrm{c}}+\mathrm{h}_{\mathrm{r}, \mathrm{p}-\mathrm{c}}\right) \mathrm{T}_{\mathrm{c}}+\left(-\mathrm{h}_{c, \mathrm{p}-\mathrm{c}}-\mathrm{h}_{\mathrm{r}, \mathrm{p}-\mathrm{c}}\right) \mathrm{T}_{\mathrm{p}}+\mathrm{OT}_{\mathrm{f}}+\mathrm{OT}_{\mathrm{b}}$

The heat balance equations for the V-grooved absorber derived from the thermal network shown from Eqs. (4) to (6).

$I_{t} \alpha_{p} \tau_{c}=\left(h_{c, p-c}+h_{r, p-c}\right)\left(T_{p}-T_{c}\right)+h_{r, p-b}\left(T_{p}-T_{b}\right)+h_{c, p-f}\left(T_{p}-T_{f}\right)$

$I_{t} \alpha_{p} \tau_{c}=\left(h_{c, p-c}+h_{r, p-c}\right) T_{p}-\left(h_{c, p-c}+h_{r, p-c}\right) T_{c}+\left(h_{r, p-b}\right) T_{p}-\left(h_{r, p-b}\right) T_{b}+\left(h_{c, p-f}\right) T_{p}-\left(h_{c, p-f}\right) T_{f}$

$I_{t} \alpha_{p} \tau_{c}=\left(-h_{c, p-c}-h_{r, p-c}\right) T_{c}-\left(h_{c, p-c}+h_{r, p-c}+h_{r, p-b}+h_{c, p-f}\right) T_{p}-\left(h_{c, p-f}\right) T_{f}-\left(h_{r, p-b}\right) T_{b}$

The airflow in the channel considering fluid and plate temperatures is described in Eqs. (7) to (11)

$h_{c, p-f}\left(T_{p}-T_{f}\right)=h_{c, f-b}\left(T_{f}-T_{b}\right)+q_{u}$

$T_{f o}-T_{f i}=\frac{q_{u} W L}{m c} ; T_{f}=\frac{T_{f i}+T_{f o}}{2} ; T_{f o}=2 T_{f}-T_{f i}$ and $q_{u}=\frac{m c\left(2 T_{f}-T_{f i}\right)-T_{f i}}{W_{L}}$

The details heat gain factors found substituting Eq. (8) into Eq. (7), results inEq. (9)

$h_{c, p-f}\left(T_{p}-T_{f}\right)=h_{c, f-b}\left(T_{f}-T_{b}\right)+\frac{2 m c}{W L}\left(T_{f}-T_{i n}\right)$

$\left(h_{c, p-f}\right) T_{p}-\left(h_{c, f-b}\right) T_{f}=\left(h_{c, f-b}\right) T_{f^{-}}\left(h_{c, f-b}\right) T_{b}+\frac{2 m c}{W L} T_{f}-\frac{2 m c}{W L} T_{i n}$

$O T_{c}+\left(h_{c, p-f}\right) T_{p}+\left(-h_{c, p-f}-h_{c, f-b}-\frac{2 m c}{W L}\right) T_{f}+\left(h_{c, f-b}\right) T_{b}=-\frac{2 m c}{W L} T_{i n}$

The heat balance equations of the back-plate described in Eqs. (12) to (14).

$h_{c, f-b}\left(T_{f}-T_{b}\right)+h_{r, p-b}\left(T_{p}-T_{b}\right)=U_{b}\left(T_{b}-T_{a}\right)$

$\left(h_{c, f-b}\right) T_{f}-\left(h_{c, f-b}\right) T_{b}+\left(h_{r, p-b}\right) T_{p}-\left(h_{r, p-b}\right) T_{b}=U_{b} T_{b}-U_{b} T_{a}$

$O T_{c}+\left(h_{r, p-b}\right) T_{p}+\left(h_{c, f-b}\right) T_{f}+\left(-h_{c, f-b}-h_{r, p-b}-U_{b}\right) T_{b}=-U_{b} T_{a} \rightarrow h_{c, p-f}=h_{c, f-b}$

$Q_{u}=F_{R} A_{P}\left[I(\tau \alpha)-U_{L}\left(T_{0}-T_{i}\right)\right]$

$F_{R}=\frac{\dot{m}}{U_{1}} \frac{C_{P}}{A_{P}}\left[1-\exp \left\{-\frac{F^{\prime}}{\dot{m}} \frac{U_{1} A_{P}}{C_{P}}\right\}\right]$

$F^{\prime}=\left(1+\frac{U_{l}}{h}\right)^{-1}$

$\mathrm{U}_{\mathrm{b}}=\frac{\mathrm{k}_{\mathrm{i}}}{\mathrm{t}_{\mathrm{i}}} \quad$ and $\mathrm{U}_{\mathrm{s}}=\frac{(\mathrm{L}+\mathrm{W}) \mathrm{Hk}_{\mathrm{i}}}{\mathrm{LWt_{ \textrm {i } }}}, \mathrm{U}_{\mathrm{t}}=\left[\frac{\mathrm{M}}{\left(\frac{\mathrm{c}}{\mathrm{T}_{\mathrm{pm}}}\right)\left(\frac{\mathrm{T}_{\mathrm{pm}}-\mathrm{T}_{\mathrm{a}}}{\mathrm{M}+\mathrm{f}}\right)^{0.33}}+\frac{1}{\mathrm{~h}_{\mathrm{w}}}\right]^{-1}+\left[\frac{\sigma\left(\mathrm{T}_{\mathrm{pm}}^{2}+\mathrm{T}_{\mathrm{a}}^{2}\right)\left(\mathrm{T}_{\mathrm{Pm}}+\mathrm{T}_{\mathrm{a}}\right)}{\frac{1}{\varepsilon_{\mathrm{p}+0.05 \mathrm{M}\left(1-\mathrm{e}_{\mathrm{p}}\right)}+\frac{(2 \mathrm{M}+\mathrm{f}-1)}{\varepsilon_{\mathrm{c}}}-\mathrm{M}}}\right]$

$\mathrm{U}_{\mathrm{L}}=\mathrm{U}_{\mathrm{s}}+\mathrm{U}_{\mathrm{b}}+\mathrm{U}_{\mathrm{t}}$ 


$$
\begin{aligned}
& \eta_{\mathrm{th}}=\frac{\mathrm{Q}_{\mathrm{u}}}{\mathrm{LA}_{\mathrm{P}}}=\mathrm{F}_{\mathrm{R}}\left\{(\alpha \tau)-\frac{\mathrm{U}_{\mathrm{L}}\left(\mathrm { U } _ { \mathrm { L } } \left(\mathrm{T}_{\mathrm{o}}-\mathrm{T}_{\mathrm{i}}\right.\right.}{\mathrm{I}}\right\} \\
& \frac{\partial \rho}{\partial \mathrm{t}}+\nabla \cdot(\rho \mathrm{V})=0 \\
& \frac{\partial(\rho \mathrm{u})}{\partial \mathrm{t}}+\nabla \cdot(\rho \mathrm{uV})=\frac{\partial \mathrm{p}}{\partial \mathrm{x}}+\mu \nabla(\nabla \cdot \mathrm{u})+\rho \mathrm{g}_{\mathrm{x}} \\
& \frac{\partial(\rho \mathrm{v})}{\partial \mathrm{t}}+\nabla \cdot(\rho \mathrm{vV})=\frac{\partial \mathrm{p}}{\partial \mathrm{x}}+\mu \nabla(\nabla \cdot \mathrm{v})+\rho \mathrm{g}_{\mathrm{y}} \\
& \rho \mathrm{C}_{\mathrm{P}}\left(\frac{\mathrm{dT}}{\mathrm{dt}}+\nabla(\mathrm{TV})\right)=\nabla(\nabla \cdot \mathrm{kT}) \\
& \mathrm{R}_{\mathrm{e}}=\frac{\text { Inertia force }}{\text { viscous force }}=\frac{\rho \mathrm{u} \mathrm{D}}{\mu} \\
& \mathrm{D}_{\mathrm{n}}=\mathrm{R}_{\mathrm{e}} \sqrt{\frac{\mathrm{D}_{\mathrm{H}}}{\mathrm{R}_{\mathrm{C}}}}
\end{aligned}
$$

Collecting Eqs.(1) to (14), substituting one into another, and rearranging equations to $4 X 4$ matrix can find mean temperatures of the collector, plate, fluid, and backplate.

Where, I is solar radiation, $\left(w m^{-2}\right), \mathrm{h}$ is the coefficient of heat transfer, $\left(w m^{-2} k\right)$, T is temperature, $(\mathrm{K}), \alpha$ is solar absorbance of collector plate, $\tau$ is solar transmittance of glazing, $\mathrm{U}$ is overall heat loss coefficient, $\left(\mathrm{wm}^{-2} \mathrm{k}\right), Q_{u}$ rate of useful energy gain, (W), L is collector length,(m), $\mathrm{w}$ is collector width, $(\mathrm{m}), \dot{m}$ is collector flowrate, $\left(\mathrm{kgs}^{-1}\right)$, and subscripts; $\mathrm{a}$ is ambient, $\mathrm{b}$ is back, $\mathrm{c}$ is cover, $\mathrm{f}$ is fluid, $\mathrm{p}$ is the plate, $\mathrm{w}$ is the wind, $i$ is an inlet.

\section{Thermal Energy Harvesting and Efficiency}

The amount of useful energy gained indicates the performance of a collector calculating the difference in absorbed solar radiation and thermal heat loss. The thermal efficiency of the solar air heater can be determined from the equation given by Duffie and Beckmann, (1991) and Sukhatme and Nayak, (2008)

Where; $F_{R}$ is the collector heat removal factor, $A_{P}$ is the area of the collector that absorber solar radiation, $\left(m^{2}\right), U_{L}$ is overall heat loss coefficient, $\left.w m^{-2} k\right),(\tau \alpha)$ is the product of transmittance-absorbance glass cover (15).

Where; $F^{\prime}$ is collector efficiency factor (16). The expression for coefficients indicating bottom loss, $U_{b}$, side loss, $U_{s}$, and top loss, $U_{t}$ are given as follows (17).

Where;

$$
\begin{aligned}
& \mathrm{f}=\left(1-0.04 \mathrm{~h}_{\mathrm{w}}+0.0005 \mathrm{~h}_{\mathrm{w}}^{2}\right)(1+0.091 \mathrm{M}) \\
& \mathrm{C}=365.9\left(-0.00883 \beta+0.0001298 \beta^{2}\right) \\
& \mathrm{M}=\text { number of glass covers }(18) .
\end{aligned}
$$

Overall heat loss coefficient (U_L) is sum of top loss, bottom loss and side loss coefficients (Duffie and Beckmann 1991). (19).

The expression for thermal efficiency $\left(\eta_{t h}\right)$ is given by

Since the inlet air temperature is equivalent to ambient air temperature, it is convenient to calculate as a function of outlet air temperature which is evident for the result expression of thermal efficiency $\left(\eta_{\text {th }}\right)$ is more practical (20)

\section{Description of the Computational Model}

The computational domain considered includes a rectangular flat plate and V-grooved surface fixed to the middle of the flow channel straight connected to the dryer cabinet. The borehole size for hot air entrance is $2-3 \mathrm{~mm}$ in diameter. In all simulation cases, the discretized flow domain in unstructured three-dimensional mesh was created and the finite volume method was selected for all geometries.

\section{Boundary Conditions}

Throughout the numerical analysis, two equations of the viscous $\mathrm{k}-\varepsilon$ turbulence model were selected. The fluid flows in two- dimensional domain, steady-state, incompressible, density-based, and absolute solver type were preferred. The flow domain of the inlet section was set to mass flow rate, $\mathrm{kg} / \mathrm{s}$ and pressure outlet selecting air as a fluid material. For the small temperature rise, air possesses low thermophysical properties and throughout the simulation process, all physical properties are assumed to be constant at a temperature of 300 $\mathrm{k}$ as shown in Table 1.

\section{Selecting Physics Models and Governing Equations}

The model uses the SIMPLE algorithm for pressurevelocity coupling and steady-state numerical analysis to solve the discretized computational flow domain. For the twodimensional numerical analysis, governing equations i.e. energy, $\mathrm{x}$ and $\mathrm{y}$ momentum, continuity, and turbulence dissipation rate $\varepsilon$ equations were solved realizing boundary conditions on the flow domain. The Convergence criteria have used $10^{-3}$ orders for the energy equation and $10^{-5}$ orders for the velocity component and momentum equation. The continuity equation is given by (21). Momentum equations are given by (22). The energy equation is given by (23). Where; $\rho$ is the density of air, $\left(\mathrm{Kg}_{\mathrm{m}} \mathrm{m}^{-3}\right), \mathrm{V}$ is the fluid Volume, $\left(\mathrm{m}^{3}\right), u, v$ is the velocity in $\mathrm{x}$ and $\mathrm{y}$ direction respectively, $\left(m . s^{-1}\right), \mathrm{T}$ is Temperature, $(k), \mathrm{K}$ is thermal conductivity, $\left(w . m^{-1} \cdot k^{-1}\right), \rho g$ indicates force density, $\nabla$ represents gradient concerning space. Reynolds and Dean Number calculated from Eqs. (24) and (25) respectively. 


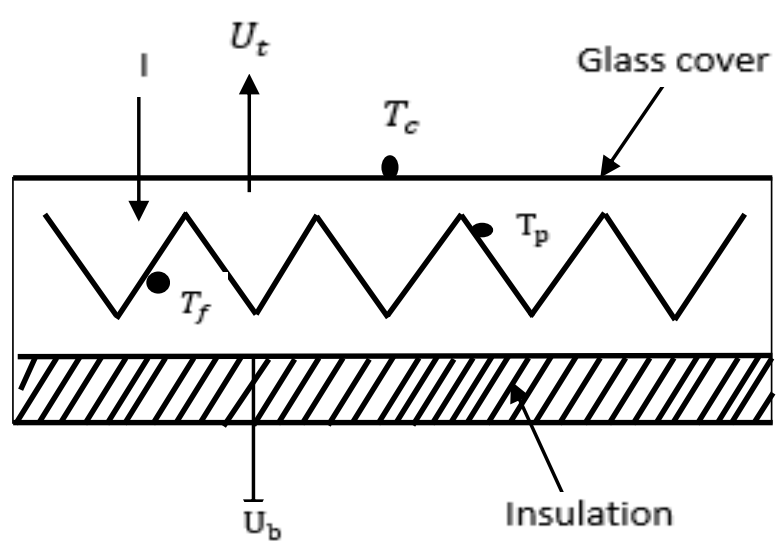

Figure 2. Schematic representation of solar air collector

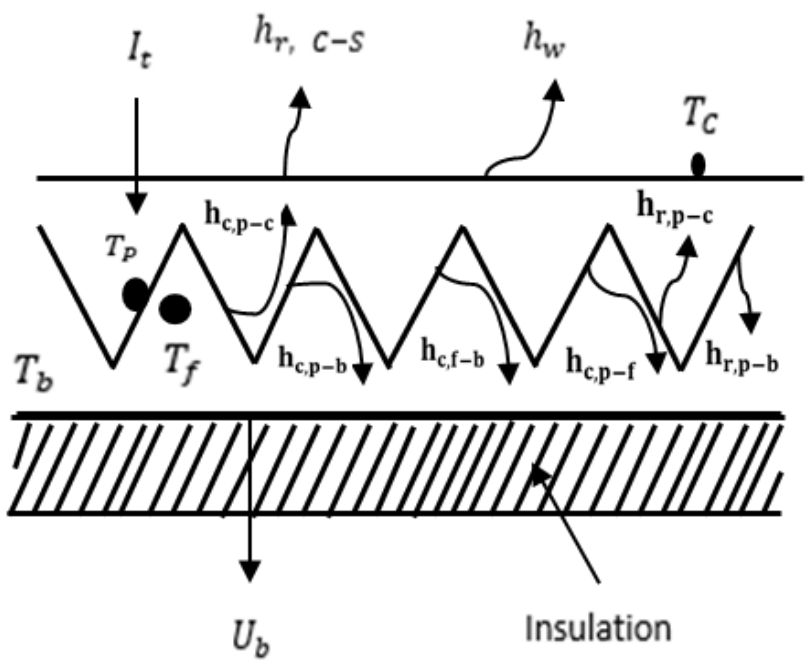

Figure 3. Schematic representation of collector illustrating heat transfer and heat loss

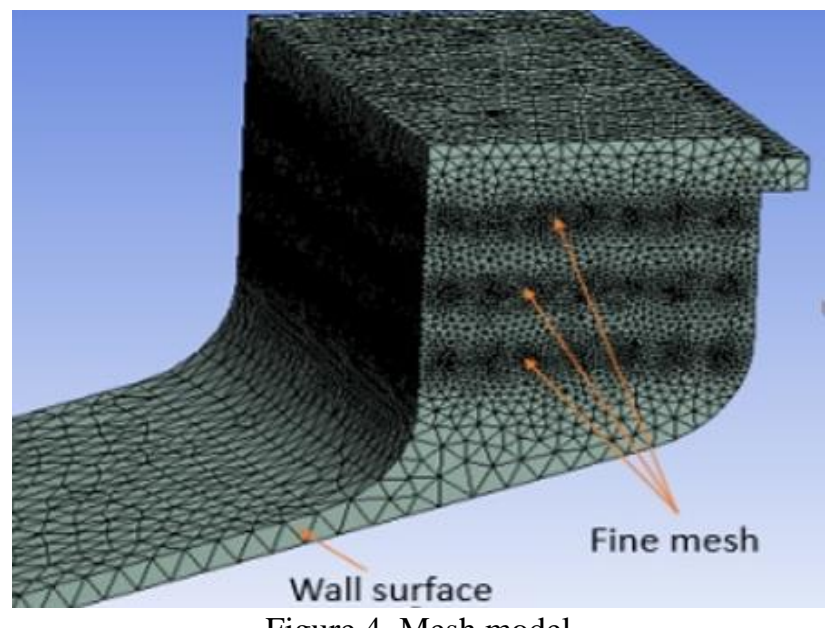

Figure 4. Mesh model

Table 1: Thermo-physical properties of air at $300 \mathrm{~K}$

\begin{tabular}{l|c}
\hline \multicolumn{1}{c|}{ Properties name } & Value \\
\hline Dynamic viscosity, $\mu$ & $1.855 \times 10^{-5} \mathrm{~N} \mathrm{~s} / \mathrm{m}^{2}$ \\
Thermal conductivity, $\mathrm{k}$ & $0.026 \mathrm{w} / \mathrm{m} \mathrm{k}$ \\
Prandtl number, pr & 0.71 \\
Specific heat, $\mathrm{C}_{\mathrm{p}}$ & $1003.62 \mathrm{~J} / \mathrm{Kg} \mathrm{k}$ \\
Density, $\rho$ & $1.184 \mathrm{~kg} / \mathrm{m}^{3}$ \\
\hline
\end{tabular}

Source: material property tables
Where; $\rho$ is the fluid density, $\left(\mathrm{kg}^{-3} \mathrm{~m}^{-3}\right), \mu$ is the dynamic viscosity of air, (N.s. $\left.\mathrm{m}^{-2}\right)$, D is duct diameter, $(\mathrm{mm}), u$ is the speed flow, $\left(m \cdot \mathrm{s}^{-1}\right), D_{H}$ hydraulic diameter, $(\mathrm{mm}), \mathrm{RC}$ is the radius of the curvature in the path of the curved channel, $(\mathrm{mm})$, and $\mathrm{D}_{\mathrm{H}}=\mathrm{H} / 2(\mathrm{H}$ represents the height of the duct). Calculating Reynolds number and dean number is important to differentiate laminar and turbulent flow in straight and curved duct respectively (Singh, 2018). In this present work, Reynolds number and Dean number were between the range of 2209-6058 and 180-494, respectively that is in the turbulent flow range (Mahboub et al., 2016; Nivedita et al., 2017), therefore, during the entire simulation run, the turbulent flow model has been considered.

\section{Selection of the Turbulence Model}

The investigations were conducted for different turbulence models, namely; K-Epsilon turbulence, KOmega turbulence, Reynolds-Stress turbulence, and Spalart-Allmaras turbulence in two dimensional, steady, and incompressible flows. A K-Epsilon turbulence model is a two-equation model that solves transport equations for the turbulent kinetic energy $\mathrm{k}$ and its dissipation rate $\varepsilon$. The $\mathrm{K}$-Omega model is a two-equation model that solves transport equations for the turbulent kinetic energy $\mathrm{k}$ and a quantity called $\omega$, which is defined as the specific dissipation rate, i.e., the dissipation rate per unit turbulent kinetic energy $(\omega \sim \varepsilon / k)$. The Spalart-Allmaras is one equation model is a low-Reynolds number model, that it is applied without wall functions. The model can be applied on the fine mesh where the viscous sub-layer, including, the entire turbulent boundary layer can be accurately resolved. The Reynolds-stress turbulence model is a fiveequation model, also known as second-moment closure models, to solve transport equations for each component of the Reynolds stress tensor. The outlet air temperature $\left(\mathrm{T}_{\mathrm{o}}\right)$ was calculated for different Reynolds number (Re) of 6078,3650 , and 2200 where the top surface of the absorber exposed to a uniform heat flux of $900 \mathrm{w} / \mathrm{m}^{2}$ for K-Epsilon turbulence, K-Omega turbulence, Spalart-Allmaras turbulence, and Reynolds-Stress turbulence, respectively.

The surrounding heat losses from the exposure to the outer surface were assumed negligible i.e. adiabatic in simulation. The thermal efficiency of the two solar absorbers; rectangular flat plate and V-corrugated surface were also compared with experimental data as shown in Figure 9. The maximum percentage deviation of thermal efficiency has been found were $9.40 \%$ and $11.60 \%$ respectively. The pressure drops across the area also compared experimental data for the two absorbers, rectangular flat plate and $\mathrm{V}$-corrugated surface as shown in Figure 10. The maximum percentage deviation has been observed were $6.20 \%$ and $9.70 \%$ respectively. Calculating pressure ensure the availability of enough gas pressure to pass hot air through all compartments of the dryer at fullscale.

\section{Simulation Analysis and Validation of CFD Model}

To start CFD simulation, the data input was categorized into three; metrological data, specification to manufacturing attributes, and energy characteristic data; inlet temperature, and mass flow rate. The hot air will pass over the agricultural products to be dried, where convective 
heat transfer takes place. The convection medium has the opportunity of high drying rate, high moisture removal, transferring heat of evaporation of the humidity of the wet product, and evacuating the evaporated moisture.

To begin the iteration, the size parameters of the collector first determined, the temperature of glazing (Tc), absorber plate (Tp), airflow (Tf), and base plate $(\mathrm{Tb})$ are estimated as shown in the simulation flowchart.

The major characteristic of the streamline depends on velocity and represents the behaviour of fluid flowing inside the drying compartments, Figure 6 (b). The property of the convection heat transfer depends on heat flux at the surface and potential difference of temperature, but not an intrinsic property of the material. The velocity vector represents the magnitude and the direction of flow velocity, Figure 6 (a). At low flow velocities, the pressure drops also lower whereas at high flow velocity a larger pressure drops developed across a section of a pipe. This pressure drop can be due to surface roughness and change of flow direction, expressed in terms of a $90^{\circ}$ bend loss coefficient.

In solar collectors, the heat transfer capacity depends on the mass flow rate and more heat transfer from the plate to the flowing fluid. At a lower flow rate, flowing air contacts with the absorber surface area for high retention time (Shukla et al., 2018). The cause for the poor performance of flat plate collectors is due to low convective heat transfer between the absorber and air stream (Ramani et al., 2010). The types of flow patterns are among the factors affecting the efficiency of the dryer (Alam and Kim, 2017). The V-groove absorber can extract more heat from the absorber that enhances the heat transfer coefficient (El-Sebaii et al., 2011).

Increasing the mass flow rate decreases the out temperature of the collector, but thermal efficiency increases (Pakhare and Salve, 2011; Zulkifle et al., 2018). The density of hot air is lower than the density of ambient air so that is easily replaced naturally. Fluid velocity is the function of pressure gradient and resistances, but the existing sufficient velocity of the fluid creates higher turbulence and higher thermal efficiency.

Figure 8 shows that the velocity of the fluid developed during the $\mathrm{V}$-grooved absorber model ranges from 0.18 $\mathrm{m} / \mathrm{s}$ to $1.4 \mathrm{~m} / \mathrm{s}$, and in the rectangular absorber model, the velocity ranges from $0.1 \mathrm{~m} / \mathrm{s}$ to $0.40 \mathrm{~m} / \mathrm{s}$. The result obtained by most researchers in concurrency with this result (Koua et al., 2009; Gatea, 2011; Aziz et al., 2016) suggests the rage of air velocities between $0.22 \mathrm{~m} / \mathrm{s}$ to 2 $\mathrm{m} / \mathrm{s}$. (But Şevik, 2013) reported that air velocities above $0.42 \mathrm{~m} / \mathrm{s}$ do not influence the drying rate.

The numerical result of pressure drops agrees with the experimental data obtained by El-Sebaii et al., 2011 with a maximum deviation of $7.80 \%$ and $6.20 \%$ for $\mathrm{V}$-grooved and rectangular absorber respectively. In V-grooved duct, due to the presence of high velocity flow becomes more turbulent and improves thermal efficiency (Handoyo et al., 2016). Dryer performance is affected by many factors including; temperature, velocity, the moisture of the product, porosity if the product, surrounding air, layer thickness, kiln structure, and drying method (Bolaji \& Olalusi, 2008; Şevik, 2013).

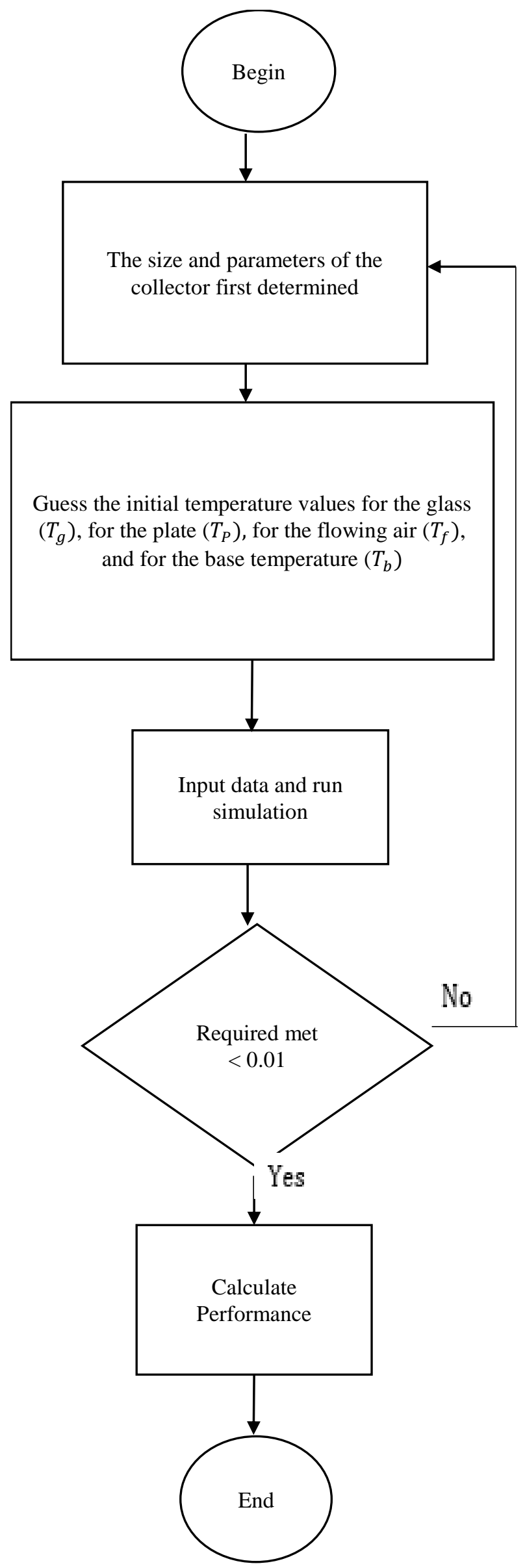

Figure 5. Simulation Flowchart 

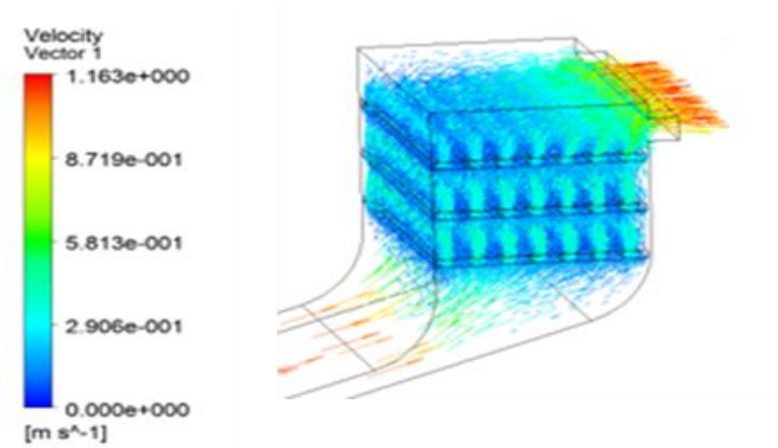

a) Velocity vector
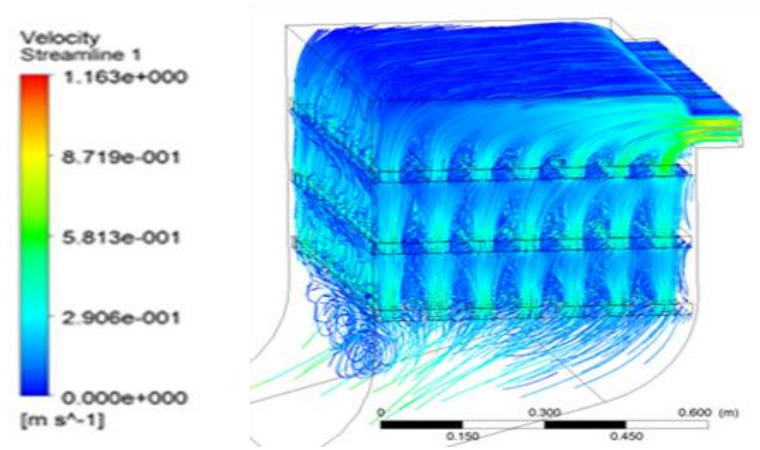

b) Velocity streamline

Figure 6. Airflow profile inside a dryer

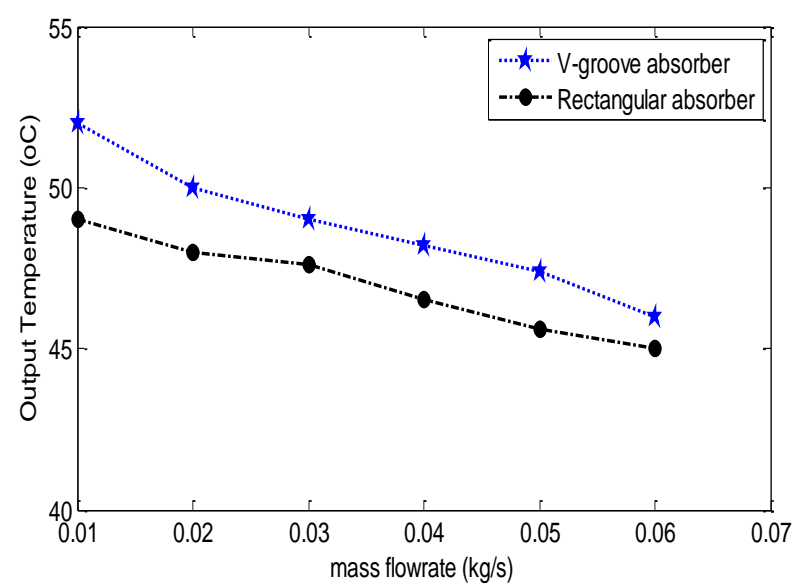

Figure 7. Influence of mass flow rate $(\mathrm{kg} / \mathrm{s})$ on outlet temperature $\left({ }^{\circ} \mathrm{C}\right)$

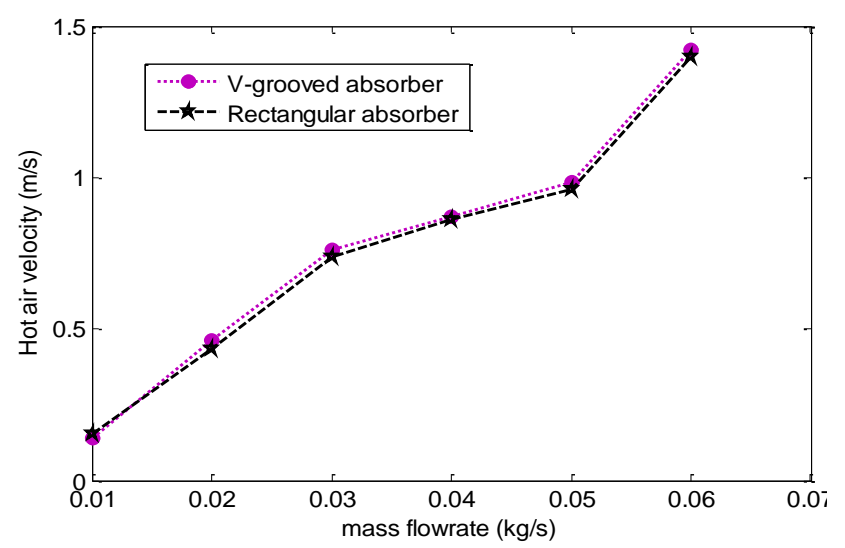

Figure 8. Influence of mass flow rate $(\mathrm{kg} / \mathrm{s})$ on hot air velocity $(\mathrm{m} / \mathrm{s})$

\section{Result and Discussion}

Increasing the mass flow rate decreases the outlet temperature. For the sample taken within a flow ranges, $0.01 \mathrm{~kg} / \mathrm{s}$ to $0.06 \mathrm{~kg} / \mathrm{s}$, high temperature observed at lower temperature range. The heat exchange takes place between the moving air and the water vapour from the wet product via convection mode. Figure 7 shows increasing mass flow rate from $0.01 \mathrm{~kg} / \mathrm{s}$ to $0.06 \mathrm{~kg} / \mathrm{s}$, decreases the output temperature. The temperature of $\mathrm{V}$-grooved absorber reaches $52^{\circ} \mathrm{C}$ at a mass flow rate of $0.01 \mathrm{~kg} / \mathrm{s}$ while the temperature of the rectangular absorber attains $49^{\circ} \mathrm{C}$ at the same flowrate. At $0.06 \mathrm{~kg} / \mathrm{s}$, the temperature of the Vgrooved absorber falls from $52^{\circ} \mathrm{C}$ to $46{ }^{\circ} \mathrm{C}$ and for the rectangular absorber falls from $49^{\circ} \mathrm{C}$ to $45^{\circ} \mathrm{CFigure} 8$ shows the response of hot airflow velocity to different flow rate passing through the drying compartment. With a flow rate of $0.01 \mathrm{~kg} / \mathrm{s}$, the velocity of hot air passing over the Vgrooved absorber attain $0.28 \mathrm{~m} / \mathrm{s}$ and increased to $1.44 \mathrm{~m} / \mathrm{s}$ as the mass flow rate increased to $0.06 \mathrm{~kg} / \mathrm{s}$. For the rectangular absorber, the velocity of hot air attains 0.15 $\mathrm{m} / \mathrm{s}$ at a flow rate of $0.01 \mathrm{~kg} / \mathrm{s}$ and increased to $1.40 \mathrm{~m} / \mathrm{s}$ as the flow rate increase to $0.06 \mathrm{~kg} / \mathrm{s}$.

The geometry of the absorber has a great role in collecting solar radiation and creating a convective media that increases the heat transfer coefficient. The absorber area significantly affects the heat transfer coefficient. Figure 9 shows the thermal efficiency of the collector versus mass flow rate. Thermal efficiency indicates the fraction of useful heat energy to solar energy collected. As the mass flow rate increases from $0.01 \mathrm{~kg} / \mathrm{s}$ to $0.06 \mathrm{~kg} / \mathrm{s}$ the thermal efficiency also increases. At a flow rate of $0.01 \mathrm{~kg} / \mathrm{s}$, the collector with a V-grooved absorber attain an efficiency of $18 \%$. As the mass flow rate increases to $0.06 \mathrm{~kg} / \mathrm{s}$, the efficiency reaches $87.4 \%$. The collector having rectangular absorber attains an efficiency of $10 \%$ at $0.01 \mathrm{~kg} / \mathrm{s}$, but increased to $74 \%$ as mass flowrate increases to 0.06 $\mathrm{kg} / \mathrm{s}$. The percentage of efficiency increased using a Vgrooved absorber was $13.4 \%$ compared with a rectangular absorber.

At a lower mass flow rate, the friction loss is lower and the amount of energy needed to surmount the friction loss is also lower. As the mass flow rate increases, the friction loss increases sharply for which the energy needed to surmount this friction loss is also high. In this analysis, a mass flow rate lower than $0.01 \mathrm{~kg} / \mathrm{s}$ and higher than $0.06 \mathrm{~kg} / \mathrm{s}$ were not considered, but the investigation of the optimum flow rate will be future work.

Pressure drop can be determined by calculating the difference of pressure entering and leaving the study area, which means the pressure line is permanently lost. It represents the ratio of the friction factors and the actual centreline length of the curvature. To pass the hot air through all the compartments of the dryer with full scale, the pressure must not high drop at the inlet of the drying chamber.

Figure 10 shows a pressure drop versus mass flow rate in the solar dryer, while V-grooved and rectangular absorbers were the two surfaces under comparison. Due to the increased velocity of airflow as the mass flow rate increases, the pressure drop also increases. The collector having a $\mathrm{V}$-groove absorber has greater turbulence flow as a result greater loss of kinetic energy and high-pressure drop. But the power needed to surmount the pressure drop developed across the flat and V-grooved absorber is negligible as many kinds of literature agree and reported. 

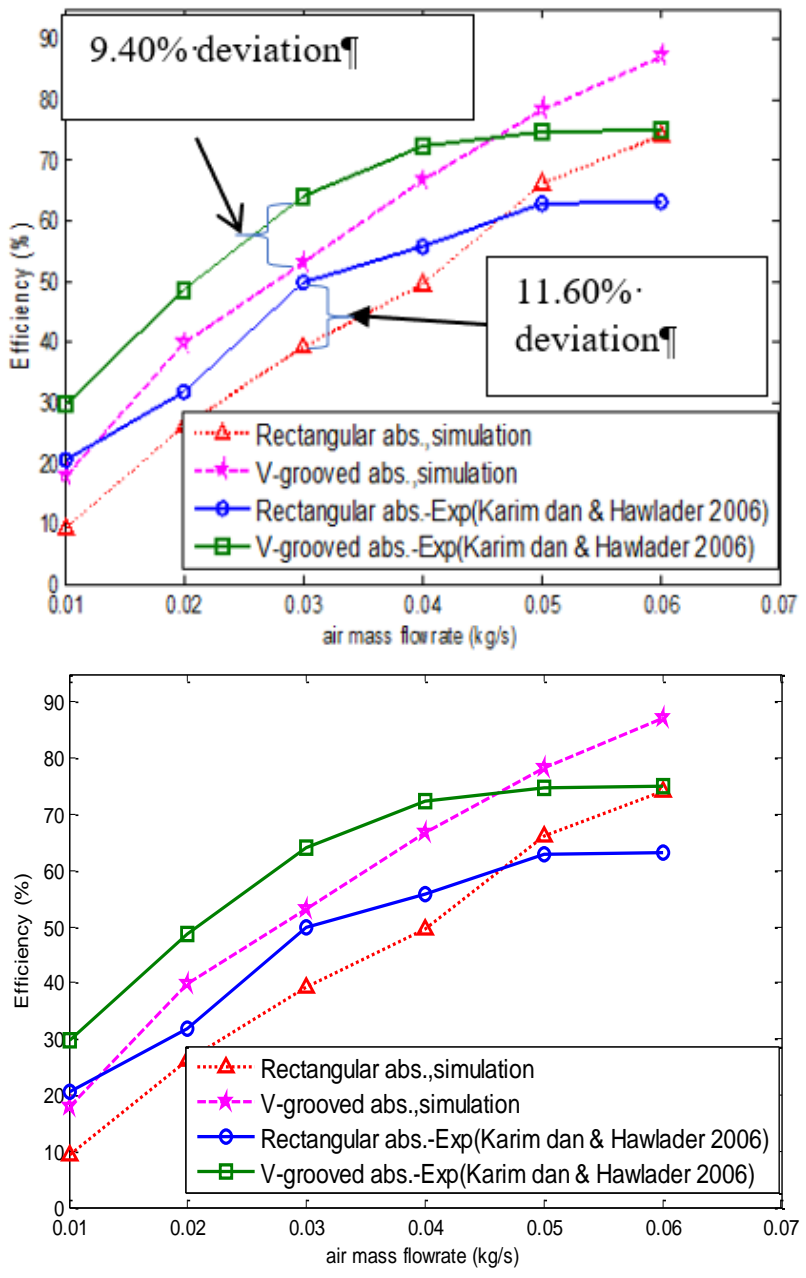

Figure 9. Effect of mass flow rate on thermal efficiency for different absorber plate

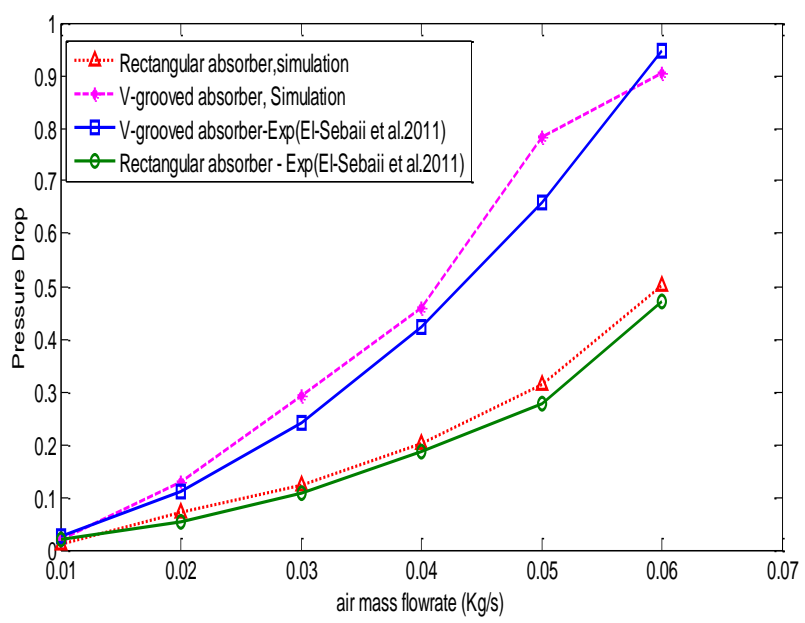

Figure 10. Influence of air mass flow rate on pressure drop

In batch drying, too high pressure has an impact on the uniformity of dried product. In the double-sided absorber, air moves both the top and bottom surface of the absorber up to the bottom region of the dryer chamber. The upward movements through the drying Compartments are not uniform due to the mixing up of two parallel moving breaths of air, and this has the advantage of increasing the retention time of heated air in the compartment

\section{Conclusion and Recommendation}

This study indicates collector's absorber has a great role to increase collector thermal efficiency and reducing the drying rate of an agricultural product while mass flow rate and environment humidity are factors affecting the system. CFD simulation has an invaluable role to predict multiple parameters with cost-effective and conduct risk-free analysis.

- Among the two-absorber in comparison, the collector with V-grooved absorber is better concerning thermal efficiency, air velocity, and output temperature.

- Keeping all factors constant including mass flow rate ranges $0.01 \mathrm{~kg} / \mathrm{s}$ to $0.06 \mathrm{~kg} / \mathrm{s}$, the collector with a $\mathrm{V}$-grooved absorber attain air velocity $0.18 \mathrm{~m} / \mathrm{s}$ to $1.4 \mathrm{~m} / \mathrm{s}$ and the collector with a rectangular absorber attain $0.1 \mathrm{~m} / \mathrm{s}$ to $0.40 \mathrm{~m} / \mathrm{s}$.

- The double-sided absorber is more desirable as it uses both the top and bottom surface of the absorber whereas the $\mathrm{V}$-grooved surface provides better thermal efficiency and output temperature.

- Hot air velocity and outlet temperature are inversely proportional to the mass flow rate because high velocity reduces the retention time of hot air.

- The larger convective surface area benefits the increasing rate of heat transfer and harvesting heat energy.

Further investigation is recommended taking the quantitative analysis obtained in this study and generating a qualitative result.

\section{References}

Alam T, Kim MH. (2017). Performance improvement of doublepass solar air heater - A state of the art of the review. In Renewable and Sustainable Energy Reviews (Vol. 79, Issue May). Elsevier Ltd. https://doi.org/10.1016/j.rser.2017 .05.087

Alam T, Saini RP, Saini JS. (2014). Experimental investigation on heat transfer enhancement due to V-shaped perforated blocks in a rectangular duct of the solar air heater. Energy Conversion and Management, 81: 374-383. https://doi.org /10.1016/j.enconman.2014.02.044

Aravindh MA, Sreekumar A. (2016). Efficiency enhancement in solar air heaters by modification of absorber plate-a review. International Journal of Green Energy, 13(12): 1209-1223. https://doi.org/10.1080/15435075.2016. 1183207

Azad MS, Chatterjee D, Layek A, Biswas DK. (2018). Thermal Performance of Solar Air Heater Having Absorber Roughened by Chamfered-Square Elements. 4(2): 24-32.

Aziz A, Ur S, Rehman SU. (2016). Exergy Analysis of Solar Cabinet Dryer and Evaluate the Performance Enhancement of Solar Cabinet Dryer by Addition of Solar Reflectors. 6(4).

Bharadwaj G, Varun Kumar R, Sharma A. (2017). Heat transfer augmentation and flow characteristics in ribbed triangular duct solar air heater: An experimental analysis. International Journal of Green Energy, 14(7): 587-598. https://doi.org/10.1080/15435075.2017.1307751

Bolaji BO, Olalusi AP. (2008). Performance Evaluation of a Mixed-Mode Solar Dryer. AU Journal of Technology, 11(4): 225-231. http://www.journal.au.edu/au_techno/2008/apr08/ journal114_article05.pdf

Burmester K, Eggers R. (2010). Heat and mass transfer during the coffee drying process. Journal of Food Engineering, 99(4): 430-436. https://doi.org/10.1016/j. jfoodeng. 2009.12.021 
Chabane F, Hatraf N, Moummi N. (2014). Experimental study of heat transfer coefficient with rectangular baffle fin of the solar air heater. Frontiers in Energy, 8(2): 160-172. https://doi org/10.1007/s11708-014-0321-y

El-Sebaii AA, Aboul-Enein S, Ramadan MRI, Shalaby SM, Moharram BM. (2011). Investigation of thermal performance of-double pass-flat and v-corrugated plate solar air heaters. Energy, 36(2): 1076-1086. https://doi.org/10.1016/j.energy. 2010.11.042

Fudholi A, Sopian K, Bakhtyar B, Gabbasa M, Othman MY, Ruslan MH. (2015). Review of solar drying systems with airbased solar collectors in Malaysia. Renewable and Sustainable Energy Reviews, 51: 1191-1204. https://doi.org/ 10.1016/j.rser.2015.07.026

Gatea AA. (2011). Design and construction of a solar drying system, a cylindrical section, and analysis of the performance of the thermal drying system. African Journal of Agricultural Research, 6(2): 343-351. https://doi.org/10.5897/AJAR 10.347

Handoyo EA, Ichsani D, Prabowo, Sutardi. (2016). Numerical studies on the effect of delta-shaped obstacles' spacing on the heat transfer and pressure drop in the v-corrugated channel of the solar air heater. Solar Energy, 131: 47-60. https://doi.org/10.1016/j.solener.2016.02.031

Ho CD, Tien YE, Chang H. (2016). Performance improvement of a double-pass V-corrugated solar air heater under recycling operation. International Journal of Green Energy, 13(15): 1547-1555. https://doi.org/10.1080/15435075.2016.1206004

Karim MA, Hawlader MNA. (2006). Performance investigation of flat plate, v-corrugated, and finned air collectors. Energy, 31(4), 452-470. https://doi.org/10.1016/j.energy.2005.03. 007

Khatibi A, Razi Astaraei F, Ahmadi MH. (2019). Generation and combination of the solar cells: A current model review. Energy Science and Engineering, 7(2): 305-322. https://doi.org/10.1002/ese3.292

Koua KB, Fassinou WF, Gbaha P, Toure, S. (2009). Mathematical modeling of the thin layer solar drying of banana, mango, and cassava. Energy, 34(10): 1594-1602. https://doi.org/10.1016/j.energy.2009.07.005

Kumar A, Kim MH. (2017). The solar air heating system with packed-bed energy-storage systems. Renewable and Sustainable Energy Reviews, 72(September 2016): 215-227. https://doi.org/10.1016/j.rser.2017.01.050

Liu T, Lin W, Gao W, Luo C, Li M, Zheng Q, Xia C. (2007). A parametric study on the thermal performance of a solar air collector with a V-groove absorber. International Journal of Green Energy (Vol. 4, Issue 6). https://doi.org/10.1080/1543 5070701665370

Madhu B, Kabeel AE, Sathyamurthy R, Sharshir SW, Manokar AM, Raghavendran PR, Chandrashekar T, Mageshbabu D. (2020). Investigation on heat transfer enhancement of conventional and staggered fin solar air heater coated with CNT-black paint — an experimental approach. Environmental Science and Pollution Research. https://doi.org/10.1007/s 11356-019-07561-1
Mahboub C, Moummi N, Brima A, Moummi A. (2016). Experimental study of new solar air heater design. International Journal of Green Energy, 13(5): 521-529. https://doi.org/10.1080/15435075.2014.968922

Nivedita N, Ligrani P, Papautsky I. (2017). Dean Flow Dynamics in Low-Aspect Ratio Spiral Microchannels. Scientific Reports, 7(March): 1-10. https://doi.org/10. 1038/srep44072

Olia H, Torabi M, Bahiraei M, Ahmadi MH, Goodarzi M, Safaei, MR. (2019). Application of nanofluids in thermal performance enhancement of parabolic trough solar collector: State-of-the-art. Applied Sciences (Switzerland), 9(3): https://doi.org/10.3390/app9030463

Prakash C, Saini RP. (2019). Use of artificial roughness for performance enhancement of solar air heaters-a review. International Journal of Green Energy, 16(7): 551-572. https://doi.org/10.1080/15435075.2019.1598418

Priyam A, Chand P. (2016). Thermal and thermohydraulic performance of wavy finned absorber solar air heater. In Solar Energy (Vol. 130). Elsevier Ltd. https://doi.org/10.1016/ j.solener.2016.02.030

Rai S, Chand P, Sharma SP. (2017). An analytical investigation on the thermal and thermohydraulic performance of offset finned absorber solar air heater. Solar Energy, 153: 25-40. https://doi.org/10.1016/j.solener.2017. 05.039

Ramani BM, Gupta A, Kumar R. (2010). Performance of a double pass solar air collector. Solar Energy, 84(11): 1929-1937. https://doi.org/10.1016/j.solener.2010.07.007

Sadeghzadeh M, Ahmadi MH, Kahani M, Sakhaeinia H, Chaji H, Chen L. (2019). Smart modeling by using artificial intelligent techniques on the thermal performance of flat-plate solar collectors using nanofluid. Energy Science and Engineering, 7(5): 1649-1658. https://doi.org/10.1002 /ese3.381

Şevik S. (2013). Design, experimental investigation, and analysis of a solar drying system. Energy Conversion and Management, 68: 227-234. https://doi.org/10.1016/j. enconman.2013.01.013

Shukla AP, Kushwaha R, Gupta B, Bisen A. (2018). Performance Analysis of Solar Air Heater using CFD Simulation. International Journal of Thermal Technologies, 8(01): 17711776. https://doi.org/10.14741/ijtt/v.8.1.2

Singh AP, Singh OP. (2018). Performance enhancement of a curved solar air heater using CFD. Solar Energy, 174(February): 556-569. https://doi.org/10.1016/j.solener. 2018.09.053

Tesema S. (2014). Resource Assessment and Optimization Study of Efficient Type Hybrid Power System for Electrification of Rural District in Ethiopia. International Journal of Energy and Power Engineering, 3(6), 331. https://doi.org/10.11648/ j.ijepe.20140306.16

Zulkifle I, Alwaeli AHA, Ruslan MH, Ibarahim Z, Othman MYH, Sopian K. (2018). Numerical investigation of Vgroove air-collector performance with changing cover in Bangi, Malaysia. Case Studies in Thermal Engineering, 12(July): 587-599. https://doi.org/10.1016/j.csite.2018.07. 012 